\title{
Optimization of Facility Location-Allocation Model for Base Tranceiver Station Antenna Establishment Based on Genetic Al- gorithm Considering Network Effectiveness Criteria (Case Study North of Kermanshah)
}

\author{
Dr. Farzad Amiri ${ }^{a^{*}}$ \\ ${ }^{a}$ Assistant Professor, Department of Industrial Engineering, Kermanshah University of Technology, Kermanshah, Iran
}

\begin{tabular}{l} 
ARTICLE INFO \\
\hline Keywords: \\
Base Tranceiver Station \\
(BTS) Antenna \\
Facility Location \\
Genetic Algorithm (GA) \\
Network efficiency criteria \\
Geographic Information \\
System (GIS) \\
Technical telecommunication \\
criteria
\end{tabular}

ARTICLE INFO

(BTS) Antenna

Facility Location

Genetic Algorithm (GA)

Network efficiency criteria

Geographic Information

Technical telecommunication

\begin{abstract}
The location of the base tranceiver station (BTS) antennas plays important role in the proper service and coverage of the mobile connection in each region. Proper location of these antennas is a major challenge for operators in each country, as in addition to maximum network coverage, service costs must also be acceptable and competitive. This means that in busy areas, in order to provide better service, the antennas must be greater and closer to each other. In general, the location problem is a type of optimization problem that aims to select a subset of the candidate locations to create the facilities that provide the best service at the lowest cost. To solve such problems in a reasonable time, we can use meta-heuristic algorithms to find solutions that are close to the optimal solution. Accordingly, this paper attempts to apply the genetic algorithm (GA) to find a suitable solution for finding BTS mobile antennas in north Kermanshah. To this end, a GA model is proposed that improves the location coordinates of the current BTS antennas extracted from the Geographic Information System (GIS). Comparison of model results with the status of BTS active antennas in Kermanshah shows the performance of the model.
\end{abstract}

\section{INTRODUCTION}

The human need for telecommunication services has increased significantly in the information age. Telecommunication companies (Telcos) continue to improve and develop their technologies and services as well. However, even given the fast development and invention of telecommunications technologies, the process of adopting such technologies in Telcos is not immune from emerging problems, particularly those related to the connection interference experienced by customers [1].

Base Transceiver Station (BTS) as an auxiliary signal generator is used for cellular purposes. Every activity for data exchange such as web browsing and others cannot be separated from the role of BTS. To support the smooth communication of data through BTS to be more optimal, the role of spatial data is needed. With spatial data, cellular network development such as new BTS development can be considered and plotted. The position of a BTS has been calculated based on the range of the transmitted signal. The number of base stations in urban areas is greater than in rural areas because each operator wants full signal coverage so that it can attract consumers to use the operator [2].

\footnotetext{
* Corresponding author. Tel.: +98 918132 0048; fax: +00833 8305006

E-mail address: f.amiri@kut.ac.i
} 
The facility location problem is a branch of operations research with great signicance for both practical and combinatorial optimization perspectives. The classical location problem is concerned with determining the location of a facility to optimize the allocation of facilities to customers [3].

BTS mobile telecommunication stations are part of the mobile telecommunications service network, being popular over a decade. The establishment of these stations as elements having particular characteristics as well as physical dimensions have imposed unfortunate consequences on urban areas. The severity of these consequences, due to the non-observance of the principles and rules of urban planning and the lack of consideration in this regard, is much greater than expected [4].

The installation location of BTS telecommunication antennas plays a very important role in servicing and providing appropriate coverage in the areas concerned. Meanwhile, the study of the distribution of waves in urban environments is one of the major issues in the designing of a mobile telecommunication network.

Service availability is pursued by a number of operators offering various systems and services that vary with the development of cellular radio network infrastructure, including in addition to the number and location of BTS Tower which is a compulsory requirement. If viewed from the opposite viewpoint, the density of the tower location is too high to bring some problems that affect the community. On the one hand, the increasing number of tower sites will indeed support the fulfillment of the community's need for telecommunication services. On the other hand, if development is done without coordination it will disturb the beauty of a region [5].

The deployment of many base transceiver stations (BTSs) by different telecommunication operators, scattered all over the vicinity of residence, work and schools, has become a great concern for economic reasons and exposure to radiation by the general public within the BTS environment [6]. In fact, the quality of wireless communications depends on many conditions in that area. Without being aware of these conditions, the designing of the communication network of mobile telecommunication can be impossible or at least non-optimal.

The number of Base Transceiver Station (BTS) continues to increase along with the increase in communication needs. To meet customer needs and provide the best service. So that the signal quality of the Base Transceiver Station (BTS) network is maintained, Mobile operators must always check and support the Base Transceiver Station (BTS). Therefore, an application is needed to find the shortest base transceiver station (BTS) that can run on the Android platform so that it can help technicians in optimizing the distance to the location of the Base Transceiver Station (BTS) in case of damage and maintenance [7].

Therefore, the correct locating of BTS antennas is a type of Non-deterministic Polynomial-time hard (NP-HARD) problem; in this regard, the complexity and volume of computational problems is increased exponentially by the increase in the number of demand points and service centers. In general, the issue of facility locating is an optimization problem whose purpose is to select a subset out of a set of candidate locations, so that facilities are provided that offer the most service at the lowest cost [8].

Currently, traditional methods are used to locate BTS Mobile Antennas being based on the technical and legal standards approved by the Ministry of Communications and Information Technology [9]. In many cases, the quality of service in an area is not acceptable due to the poor initial location; in order to compensate for this, there exists an inevitable need for an increase in the number of stations and ultimately the rise of costs and installation problems. 
In order to solve problems, the GA generates a set of possible solutions. Each of these solutions is evaluated using a fit function. Then new solutions are created using three operators: selection, intersection, and mutation. This will evolve the solutions. Hence, the search space evolves in a direction that achieves the optimal solution.

Using the proposed method, a significant advance takes place in the problem of locating the BTS mobile antennas and intelligentization of installed antennas after being located; in addition, these issues reduce the number of towers and their turning-on costs and increase the quality of the communication service compared to the usual way.

The main objective of this study is to determine the coordinates of the proposed points for the establishment of BTS antenna based on the network performance criteria and the GA (a case study of the north Kermanshah), with proper performance compared to the existing traditional methods.

\section{THE REVIEW OF THE RELATED LITERATURE}

\subsection{Base telecommunication stations (BTS)}

Basically, a telecommunication system requires equipment and devices that transfer and receive information (transceivers) using electronic codes which rely on radio frequency [10].

The first part that is directly connected to the mobile phone in the mobile network, is generally called "mobile antenna" and, particularly, is BTS, standing for BTS.

BTS stations are the most important part of the Global System for Mobile (GSM) network, being in a large number, they can be seen almost everywhere in the area covered by the network; the network is generally known by them. These stations communicate with each other through the direct aerial vision by microwaves, forming an integrated network and providing subscriber communications.

Base Transceiver Station (BTS) - is a transceiver and acts as interface between the Mobile Stations (MS) to the network. A BTS will have between 1 and 16 Transceivers (TRX), depending on the geography and demand for service of an area. Each TRX represents one Absolute radio frequency channel number (ARFCN). However, depending on geography, service demand and operator's network strategy and architecture, a BTS may be host up to two, three or six sectors, or a cell may be serviced by several BTSs with redundant sector coverage. Each sector is covered by sector antenna, which is a directional antenna [11].

The main tasks of BTS Include the following [12]:

- The organization of common radio channels is used in a cell, in which it receives the channel request from the Mobile Station (MS) and sends it by BSC to allocate, if possible, a channel to the Mobile Station (MS) . It also disables the channel and initiates encryption.

- Encoding the information received from BSC to send to the Mobile Station (MS) and decryption of the information received from the MS and sending it to BSC, multiplying the logical channels and sending them to the physical channels.

- Controlling radio subsets, which include setting the time for sending information by the MS, which is regularly updated and sending the results to BSC. 
- Sending the output power control signal to MS to reduce interference and optimize the power of MS.

- The operation of sending information to many units and receiving microwaves from them.

- Synchronizing the required information from pcm link and replacing the number of frames with the counter in it.

- Setting frequency parameters, output power of transmitters and receiver frequencies, as well as BTS color code.

Each BTS contains different modules, which are described.

A: Transceiver Interfaces (TRI): BTS are used consecutively for connections, in this case the control information related to the second BTS are sent.

B: Transceivers (TRX): Each Transceivers (TRX) in binary mode can serve 8 subscribers on eight temporal gateways. Depending on the location of the site, the number of them can be specified, for instance, up to 6 TRXs is introduced for any sites in crowded areas of each sector. Basically, each site has 3 sectors in three different directions, and each sector has 6 TRXs. Therefore, its capacity is displayed as $6+6+6$.

C: Local Storage Terminal

D: Transceiver Interfaces Input/output (TRI I/O) Terminal

E: Basic band switch: Determines the order of system's communication with different Image Receivers.

F: Timing: It extracts a base frequency from CLICK of Pulse Code Moduatio (PCM) line to generate carriers, transmitters and receivers as well as accurate counting of Time Division Multiple Access (TDMA) frames.

G: Transmitter mixer: mixes signals from TRX and sends them on the antenna.

H: divider: Strengthening and dividing received waves, strengthens and amplifies signals received from antennas and divides them.

I: Power converter: A converter inside the BTS that can convert Voltages Alternating Converted (VAC) 220 or Voltages Directly Converted (VDC) 66- 48 to the VDC 24 voltage required for the BTS power supply.

At the first competitive facility location model for the cognitive radio network assumed that each customer patronizes the company with the best signal quality from its nearest base station. Each customer makes own decision independently from other customers, as in the most facility location models. In this work we propose a new model for customer behavior. We assume that customers are mobile. They experience and evaluate the quality of connection over the whole network. Thus, the choice of the company (mobile operator) is made upon the average quality of service, In other words, we assume that customers can move from one operator to another until the average quality of service will be the same and customers reach the Nash equilibrium [13].

\subsection{GA Procedure}

GA as an optimization computational algorithm, taking into account a set of solutions for spots in each computational repetition, efficiently searches for different areas of the solution space. In the search mechanism, although the value of the objective function of the entire solution space is not computed, the calculated value of the objective function for each point is interfered in the averaging of the target function in all sub-spaces where that point is 
dependent on. These sub-spaces are statistically averaged in terms of objective function in a parallel manner. This mechanism is called implicit parallelism [14].

This process leads to the search for space in the regions where the statistical average of the target function is high and the possibility of an absolute optimal point in them is greater. Because in this method, unlike the single-way methods, the solution space is searched comprehensively, it is less possible to converge to a local optimal point. In 2008, Calleja and Debono, presented a method for position detection based on pattern recognition using important parameters in mobile signal by using a database of information sensitive to locations in the area under study; they concluded that the release of multiple routes does not reduce the precision of its location estimation [15].

Munene and Kiema, in a case study, selected Nairobi, Kenya, using GIS to locate of antennas BTS antennas. They concluded that if GIS database was provided, it could help in locating [16].

In 2012, Alamur et al., proposed a method based on GA that was used to capture the radio frequency of mobile networks and determine the location of the central station. In this method, using a particular type of intersection operation in the GA, they could come up with better answers [17].

\section{RESEARCH METHODS}

The present study can be considered as an empirical-applied research according to its application. Initially, the topographic map of Kermanshah city (with a scale of 1/25000) was processed through the natural resources office of the city and city neighborhood map (Research Institute of the World 2015) was processed from the municipality of Kermanshah. Required information was obtained through field surveys, consultation with experts, and data base production $[18,19]$.

The sample of this study, north of Kermanshah, ranged from 47 degrees and 08 minutes to 47 degrees and 19 minutes, east and 35 minutes to 34 degrees and 38 minutes, north.

In order to use GA to optimize the number of installed antennas, we must first enter their coordinates into the algorithm and then use the MATrix LABoratory (MATLAB) simulator to optimize them. In this study, GIS system was used and the information required by the system was entered into the system as well; meanwhile, the exact location was obtained according to the field information (interview and observation), and the final coordinates of the antennas were also obtained. Eventually, these coordinates were applied to the GA and the final locating was conducted.

Many studies have been carried out to examine the various criteria for choosing the location for the installation of BTS antenna, and in the following tables; these criteria have been shown along with their sub-criteria.

\subsection{Technical telecommunication criteria}

This group of criteria includes parameters that are related to the telecommunication operation of the station. The quality of a network is highly dependent on all technical considerations and criteria in (Table 1). 


\subsection{Construction and installation criteria}

This category includes parameters that ensure the functionality of the station. Depending on the type and model of the station that is to be installed in the desired location and in view of the equipment to be installed on the site, it is necessary to allow the equipment to be transferred and installed on the site (Table 2).

\subsection{Legal and ownership Criteria}

Regarding concerns about the harmfulness of magnetic radiation due to radiation from the antenna, sometimes neighbors and residents of the area disagree and continue to operate equipment installation prevented. Accordingly, the following criteria are taken into account when receiving eligible candidates by location of groups (Table $3)$.

\subsection{Urban Criteria}

This category includes criteria that are relevant to the social context of the area and vary in different locations (Table 4).

Using the analytical hierarchy process, along with the GIS for locating, contain three basic steps. In the first step, in order to achieve the goal of the study, the necessary criteria and sub criteria were formulated, previously presented in the form of tables.

The criteria and sub-criteria being obtained were weighed in the second step. To determine the coefficient of significance (weight), the criteria and sub criteria were compared in pairs, then these significant coefficients were considered in binary comparisons matrix. Using the approximate geometric mean, the coefficients of significance of the criteria was obtained which is equal to the division of the geometric mean of each parameter by the sum of the averages.

Delphi method was used to weigh the criteria and sub criteria. Thus, using the views of urban experts, weights of criteria and sub criteria were obtained and compared with each other; then using Excel software and the geometric mean method, the final weights of each criterion were calculated. After calculating the final weight of each of the three criteria, the weight of the sub criteria was also calculated (Table 5).

\section{RESULTS OF THE RESEARCH}

\subsection{Technical Telecommunication criteria}

After reviewing all the technical and logical sub-criteria using the binary comparison these values was obtained. (Table 6)

As the numbers in the table indicate, capacity sub criteria has the most impact and specifies that the population density in a region, and consequently the demand for calls is a very important parameter in choosing the installation location of the BTS antenna.

The sub criteria were achieved- as separate layers placed on each other- by the use of the above table and the integration of the information obtained from GIS, as well as each of the maps; combination of the information layers leads to the extraction of a (Figure 1) which includes 3 levels of prioritization. 


\subsection{The construction and installation criteria}

The following table is obtained after reviewing all of the following criteria for construction and installation using the binary comparison of the values. (Table 7)

As it is observed, costs have the most impact on this criterion, indicating that the cost of installing the antenna is a very important parameter in choosing the location of the BTS.

The sub criteria were achieved -as separate layers placed on each other- by the use of the above (Table 7) and the integration of the information obtained from GIS, as well as each of the maps; combination of the information layers leads to the extraction of a map which includes 3 levels of prioritization. (Figure 2)

\subsection{Examination of legal and ownership criteria}

Due to the similarity of legal and ownership conditions in all regions, the only sub-criteria differing in the segregated areas is described as the ownership cost in (Table 8).

Given that there is no integration of layers in this criterion, and there is only one separate map, the same map is placed as the outline map. The priority of the legal and property measures is as follows. (Figure 3 )

\subsection{The examination of the urban criteria}

According to the (Table 9), the sub criterion sensitive points has the greatest impact on this criterion, and the importance of sensitive areas and the military locations attracts a lot of attentions in this regard.

The mapping of urban priorities is achieved in this criterion considering the three parameters, the extraction of three separated maps using GIS software and their integration in (Figure 4).

\subsection{Final integration and identification of proposed locations}

In this stage, by combining the layers of the main criteria with each other, the prioritization map of the separation areas is obtained. The following chart shows the effect of sub-criteria on the finalized in percent. (Figure 5).

Therefore, based on this chart, the proposed coordinates were achieved in order to apply them to the GA in the north of Kermanshah. (Figure 6)

Given these locations, it is clear that higher priority areas have been nominated for antenna installation. The GIS has calculated all the parameters considered in this selection with different properties and the desired location.

\subsection{Comparison of proposed coordinates with existing antenna installation locations}

Nowadays, in the north of Kermanshah, 32 BTS antennas are installed in different regions, compared to the proposed map, it is realized that there is a difference between the locations of the current antennas and the proposed locations in terms of number and location. As the number of antennas has decreased from 32 to 30 antennas and their installation location has changed as well.( Figure 7)

Because the development process in urban areas, which are generally privately owned, in addition to the high cost of providing and installing antennas, requires consideration of legal considerations and related administrative procedures. An effective proposal to reduce operating time and costs is to relocate existing antennas to new locations according to the project schedule and based on the progress of relevant legal action. 


\subsection{The coordinates of the proposed GIS points}

To optimize proposed antennas obtained by GIS, we should consider the coordinates of these points in metric, and then we should apply these coordinates as the location of the antenna in MATrix LABoratory (MATLAB) software and optimize them by GA in (Table 10).

\subsection{Selecting important parameters to apply to the GA}

the optimization problem is intractable for exact solutions by conventional methods and the optimal solution cannot be reached within a reasonable time. In this section, we applied a GA-based, which could handle the respective models made for real-life problems. GA is a bio-inspired, probabilistic search method based on the natural selection method, which was initially developed by Holland. Gen et al. proved that GA would be a proper approach to acquire near-global solutions [20].

GA is based on the principle of evolution and natural genetics it has been successful in solving many optimization problems including the BTS placement problem. The design of a GA starts with solution encoding, creation of individuals that make a population, and evaluation of the individuals. During the evaluation each individual is assigned a fitness value according to a certain fitness function. Based on the fitness value, some of the better individuals are selected to seed the next generation by applying crossover and mutation to them. In GA, the variables can be represented in binary, integer, and real [21].

Using the Parato principle, out of 15 sub-criteria identified that affect location, only the percentage of impact of 5 sub-criteria (quality, sensitive points, imposed costs, quality of service and coverage) are significant, and the rest of the sub-criteria Can be ignored. (Figure 8)

\subsection{Location of applicants for contacting}

In order to run the simulation, we randomly scattered 100 users in the target area who want to make calls with the BTS antennas. The number of users to choose was arbitrary and there was no limit to the number of users and their location. In our research, we have considered the number of users as 100 people due to the quality of the output images and their resolution. The random coordinates generated in simulator software are shown in (Figure 9).

The location of users on the map is obtained by applying the coordinates of the points in which the users made calls (Figure 10).

\subsubsection{The examination of the number of BTS antennas and the cost of providing service, with random selection}

Considering that the number of users requested to make calls is 100 people and they are randomly dispersed across the region, and each user makes an average of five calls, and the number of 30 antennas extracted from the GIS are installed at locations with specified coordinates, the random algorithm can be used for selecting the initial population, the number of active antennas and coverage being shown in (Figure 11).

By reviewing (Figure 11), it is realized that 22 randomly selected primary populations are used, 22 antennas are active and 8 other antennas remain inactive; obviously this is the case if all 100 callers are contacted by the closest antenna.Therefore, the cost reduction is expected. This cost reduction is shown in (Figure 12).

According to the above, it can be seen that at the beginning of the algorithm and for providing communication services with 30 BTS antennas and 100 users (each of which made 5 calls), the service cost will be 1.75 multiplied 
by 10 and exponent 7, and at the end of the algorithm, this value (after 100 repetitions) will be 1.49 multiplied by 10 and exponent 7. In addition, it is assumed that the algorithm is uniform after the repetition of 34; and the excessive repetition of this amount does not contribute to the improvement of the algorithm.

\subsubsection{The examination of the number of BTS antennas and the cost of providing the services being based on the tournament method of population selection}

With the same conditions that were considered in the random population selection method, if we use the initial population selection method as a tournament, the number of active antennas and how to cover users is shown in the (Figure 13)

It should be noted that in this method, 8 antennas have been inactive. However, the location of inactive antennas has changed slightly. (Figure 13)

The cost reduction chart in this method is as follows in (Figure 14).

Using this method of selection, it can be observed that the algorithm has converged much faster, and the final value is obtained in the 29th iteration; in addition, the cost reduction of service in this method is not significantly different from the random method.

\subsubsection{The examination of the number of BTS antennas and the cost of providing service, with the selec- tion method Roulette wheel}

In a similar way to the previous two methods, if we use the roulette wheel method, the number of antennas and how to cover users is shown in the (Figure 15).

It should be noted that in this method, 8 antennas have been inactive. There is no significant changes over the previous method. The reduction cost' chart is as follows in (Figure 16).

In this population selection method, it is observed that the algorithm has reached the final value in iteration 28 and faster convergence was observed compared to the previous two methods. Also, the amount of cost reduction in this method is more than the other two methods.(1.485 multiplied by 10 to the power of 7 )

\section{CONCLUSIONS}

The observation of the results obtained by the alternate implementation of the algorithm shows that the integration of this innovative method GA being deployed on the points which were originally based on a traditional methods GIS, resulted in a faster convergence of results and, effective reduction the number of antennas, and significantly reduction of the service costs.

This reduction in the total number of antennas and service costs is due to the intelligent determination of active and inactive antennas at any given time.

Accordingly, the final output results of the GA obtained using the roulette wheel pattern in convergence 28 are shown on the geographical map of the region. Yellow dots (location of available antennas), red dots (active antenna) and green dots (inactive antenna) (Figure 17). 


\section{REFERENCES}

1- Akhriza, T., Sahaduta, H., Susilo A., "Mproving mobility of base transceiver station locating method using telegram's application", International Journal of Technology, 1, pp. 177-178 (2017).

2- Nizamuddin E., "Spatial analysis for calculating closest distance of operators' location to Base Transceiver Station (BTS) in Banda Aceh city", IOP Conf. Ser.: Mater. Sci. Eng., 796, pp. 1-2 (2020).

3- Yousefi Yegane, B., Nakhai Kamalabadi, I., Farughi H., "Influence of two different producers in a competitive location problem", Scientia Iranica, 27(5), pp. 2539-2540 (2020).

4- Shi'a I., "Introduction to the Basics of Urban Planning", Publications of the University of Science and Technology (10 $0^{\text {th }}$ edition), 3, pp. 27-35 (2001).

5- Mauludiyanto, A., Pranata, Y., "Planning of Number and Location of New Base Transceiver Station (BTS) Tower in Mobile Telecommunication System in Jombang Using Analytical Hierarchy Process Method and Geographic Information System Approach", Journal on Advance Research in Electrical Engineering, 3(2), pp. 78-79 (2019).

6- Ajibola, T., Surajudeen-Bakinde, N., Amuda, S., "Development of base transceiver station selection algorithm for collocation arrangement", Nigerian Journal of Technology (NIJOTECH), 34(3), pp. 538-539 (2015).

7- Mekongga I., Aryanti A., "The Shortest Path Search Application for Base Transceiver Station (BTS) Using A* Algorithm", Atlantis Highlights in Engineering, 7, pp. $472-473$ (2020).

8- Yaghini, M., "Novel Optimization Algorithms", The University Press, 9(2), pp. 65-74 (2016).

9- Montazeri-Gh, M., Mahmoodi-K, M., “An optimal energy management development for various configuration of plug-in and hybrid electric vehicle", Journal of Central South University, 22(5), pp. 1737-1747 (2015).

10- Elehinafe, F., Ayeni, A., Mamudu, A., Odunlami, O., Abatan, O., Folayan, A., Sonibare J., "Assessment of environmental impact of telecommunication base transceivers stations in residential areas", IOP Conference Series: Earth and Environmental Science, 655, pp. 12-66 (2021).

11- Obinna, I., Osawaru, O., "Modelling of Power Consumption in Two Base Stations, Using Ugbor Station and Benson Idahosa University Station in Benin City as a Case Study", International Journal of Innovative Science and Research Technology, 5(6), pp. 1153-1154. (2020).

12- Mohammad Pour, K., "Principles of Wireless and Mobile Communications", Khaja Nasir al-Din Tusi University of Technology Publication, 4(1), pp. 25-39. (2009).

13- Davydov, I., Kochetov, Y., Dempe, S., "Local search approach for the competitive facility location problem in mobile networks", International Journal of Artificial Intelligence, 16(1), pp. 130-132. (2018).

14- Bavari, A., Salehi, M., "Genetic Algorithms and Optimization of Composite Structures", Tehran, Abed Publication, 7(2), pp. 39-48. (2008).

15- Calleja, C., Debono, C., "The application of database correlation methods for location detection in GSM networks, In Proc. Communications", Control and Signal Processing, ISCCSP 2008, 3rd International Symposium on, 18(1), pp. 1324-1329. (2008). 
16- Munene, E., Kiema, J., "Optimizing the Location of Base Transceiver Stations in Mobile Communication Network Planning: Case study of the Nairobi”, International Interdisciplinary Journal of Scientific Research, 6(2), pp. 117-128. (2014).

17- Alamur, S., Kara, B., Karasan, O., "Multimodal hub location and hub network design”, Omega, 40, pp. 927939. (2012).

18- Zebardast, E., "Application Analytical Hierarchy Process in Urban and Regional Planning", Journal of Fine Arts, 10, pp. 47-58. (2001).

19- Golmohammadi, A., "Tavakkoli-Moghaddam, R., Jolai, F., Golmohammadi, A., Concurrent cell formation and layout design using a genetic algorithm under dynamic conditions", UCT Journal of Research in Science, Engineering and Technology, 2(1), pp. 08-15. (2014).

20- Entezaria, Z., Mahootchia, M., “Developing a mathematical model for staff routing and scheduling in home health care industries: Genetic Algorithm based solution scheme”, Scientia Iranica, 5(2), pp. 75-82. (2020).

21- Nwelih, E., Asagba P., Ugwu C., "Design and Implementation of Neighborhood Control Optimal GSM Base Transceiver Station Placement Using Genetic Algorithm", Afr. J. Comp, \& ICT, 11(1), pp. 12-27. (2018).

\section{Biographies}

Farzad Amiri is the assistant professor of Industrial Engineering at Kermanshah University of Technology (KUT). received the B.S. degree in Civil Engineering from Bo ali sina University, Hamedan, Iran, in 1994, and his M.S. and Ph.D. in Industrial Engineering, System Management and Productivity , from the University of Science and Technology, Tehran, Iran, in 2004 and 2013, respectively. His current research interests include Metaheuristic Optimization, Statistical Quality Control, Project Management and System Dynamic. He is a member of the Iranian Industrial Engineering Society, Project Management Society and Civil Engineering Society.

Table 1. Technical Telecommunication criteria

\begin{tabular}{|c|c|c|}
\hline Criterion & Sub criteria & DESCRIPTION \\
\hline \multirow{5}{*}{$\begin{array}{l}\text { Technical tele- } \\
\text { communication }\end{array}$} & Capacity & Demand is determined based on population density \\
\hline & Coverage & The area under coverage and the coverable areas are specified \\
\hline & Service level & $\begin{array}{l}\text { Describes traffic congestion and whether the system is allowed to } \\
\text { block several percent of subscriber calls }\end{array}$ \\
\hline & Service quality & How much is the implementation quality of the system \\
\hline & $\begin{array}{l}\text { Expansion Abil- } \\
\text { ity }\end{array}$ & $\begin{array}{l}\text { Prospects for the future projects and the development plan in the } \\
\text { preliminary design should be considered }\end{array}$ \\
\hline
\end{tabular}

Table 2. Construction and installation criteria 
Optimization of Facility Location-Allocation Model for Base Tranceiver Station ...

\begin{tabular}{|c|c|c|}
\hline Criterion & Sub criteria & DESCRIPTION \\
\hline \multirow{3}{*}{$\begin{array}{c}\text { Construc- } \\
\text { tion and in- } \\
\text { stallation }\end{array}$} & $\begin{array}{c}\text { Enough space to de- } \\
\text { ploy equipment }\end{array}$ & $\begin{array}{r}\text { Availability of sufficient space to deploy equipment and predict the } \\
\text { space needed for potential development }\end{array}$ \\
\cline { 2 - 3 } & Power supply & $\begin{array}{r}\text { Whether is it possible to use urban power supply and if not, is it pos- } \\
\text { sible to use emergency electricity for power supply }\end{array}$ \\
\cline { 2 - 3 } & Cost & Check the required location for strength \\
\cline { 2 - 3 } & Congth & The cost of installing the antenna is considered \\
\hline
\end{tabular}

Table 3. Legal and ownership Criteria

\begin{tabular}{|c|c|c|}
\hline Criterion & sub criteria & DESCRIPTION \\
\hline \multirow{3}{*}{$\begin{array}{c}\text { Legal and } \\
\text { ownership } \\
\text { Criteria }\end{array}$} & The possibility of signing contracts & $\begin{array}{c}\text { The satisfaction of the owner or the owners and the } \\
\text { possibility to sign contracts are reviewed }\end{array}$ \\
\hline & $\begin{array}{c}\text { The lack of ownership and legal } \\
\text { problem }\end{array}$ & $\begin{array}{c}\text { The location is carefully considered in terms of lack of } \\
\text { ownership and legal problems }\end{array}$ \\
\hline & Ownership Costs & $\begin{array}{c}\text { The costs of ownership including buying or renting } \\
\text { should be considered }\end{array}$ \\
\hline
\end{tabular}

Table 4. Urban criteria

\begin{tabular}{|c|c|c|}
\hline Criterion & sub criteria & DESCRIPTION \\
\hline \multirow{3}{*}{ Urban } & sensitive points & $\begin{array}{c}\text { sensitive points such as hospitals, gyms and military centers are consid- } \\
\text { ered }\end{array}$ \\
\cline { 2 - 3 } & Traffic & Traffic of the target area is evaluated \\
\cline { 2 - 3 } & $\begin{array}{c}\text { Communication } \\
\text { paths }\end{array}$ & Important paths are taken into consideration \\
& &
\end{tabular}

Table 5. The binary comparison of the criteria and the determination of the significant coefficients (weight)

\begin{tabular}{|c|c|c|c|c|c|c|}
\hline The main criteria & $\begin{array}{c}\text { Technical telecom- } \\
\text { munication }\end{array}$ & $\begin{array}{c}\text { Construction } \\
\text { and installa- } \\
\text { tion }\end{array}$ & $\begin{array}{c}\text { Legal and } \\
\text { ownership }\end{array}$ & urban & $\begin{array}{c}\text { Geometric } \\
\text { mean } \\
\text { weight }\end{array}$ \\
\hline $\begin{array}{c}\text { Technical telecommuni- } \\
\text { cation }\end{array}$ & 1 & 7 & 5 & 3 & 3.20 & 0.54 \\
\hline $\begin{array}{c}\text { Construction and instal- } \\
\text { lation }\end{array}$ & 0.14 & 1 & 0.33 & 0.20 & 0.41 & 0.07 \\
\hline
\end{tabular}


Dr. Farzad Amiri.

\begin{tabular}{|c|c|c|c|c|c|c|}
\hline Legal and ownership & 0.20 & 3 & 1 & 0.20 & 0.59 & 0.10 \\
\hline urban & 0.33 & 5 & 5 & 1 & 1.7 & 0.29 \\
\hline \multicolumn{2}{|c|}{ Total } \\
\hline
\end{tabular}

Table 6. The binary comparison of Technical Telecommunication sub criteria

\begin{tabular}{|c|c|c|c|c|c|c|c|c|}
\hline Row & Capacity & Cover & $\begin{array}{c}\text { Service } \\
\text { level }\end{array}$ & $\begin{array}{c}\text { Services qual- } \\
\text { ity }\end{array}$ & $\begin{array}{c}\text { Expandabil- } \\
\text { ity }\end{array}$ & $\begin{array}{c}\text { Geometric } \\
\text { mean }\end{array}$ & $\begin{array}{c}\text { Standard } \\
\text { weight }\end{array}$ & $\begin{array}{c}\text { Original } \\
\text { weight }\end{array}$ \\
\hline Capacity & 1 & 3 & 5 & 3 & 7 & 3.15 & 0.50 & 0.270 \\
\hline Coverage & 0.33 & 1 & 3 & 3 & 5 & 1.1 & 0.17 & 0.0950 \\
\hline Service level & 0.20 & 0.33 & 1 & 0.33 & 5 & 0.64 & 0.10 & 0.0560 \\
\hline $\begin{array}{c}\text { Service qual- } \\
\text { ity }\end{array}$ & 0.33 & 0.33 & 3 & 1 & 3 & 0.16 & 0.0890 \\
\hline Expandability & 0.14 & 0.20 & 0.20 & 0.33 & 1 & 0.29 & 0.046 & 0.0264 \\
\hline
\end{tabular}

Table 7. The binary comparison of construction and installation sub criteria

\begin{tabular}{|c|c|c|c|c|c|c|c|}
\hline Row & $\begin{array}{c}\text { Enough space to } \\
\text { establish equip- } \\
\text { ment }\end{array}$ & $\begin{array}{c}\text { round } \\
\text { strength }\end{array}$ & $\begin{array}{c}\text { Power } \\
\text { supply }\end{array}$ & Costs & $\begin{array}{c}\text { Geometric } \\
\text { mean }\end{array}$ & $\begin{array}{c}\text { Standard } \\
\text { weight }\end{array}$ & $\begin{array}{c}\text { Original } \\
\text { weight }\end{array}$ \\
\hline $\begin{array}{c}\text { Enough space } \\
\text { to establish } \\
\text { equipment }\end{array}$ & 1 & 0.33 & 0.20 & 0.20 & 0.33 & 0.068 & 0.005 \\
\hline $\begin{array}{c}\text { ground } \\
\text { strength }\end{array}$ & 3 & 1 & 0.20 & 0.33 & 0.20 & 0.041 & 0.003 \\
\hline Power supply & 5 & 5 & 1 & 33 & 1.70 & 0.35 & 0.0245 \\
\hline Costs & 5 & 3 & 3 & 1 & 2.6 & 0.54 & 0.038 \\
\hline \multicolumn{2}{|c|}{ total } & & & 4.84 & 1 & 0.07 \\
\hline
\end{tabular}

Table 8. The binary comparison of legal and ownership sub criteria 
Optimization of Facility Location-Allocation Model for Base Tranceiver Station ...

\begin{tabular}{|c|c|c|c|c|c|c|}
\hline Row & $\begin{array}{c}\text { The possibil- } \\
\text { ity of con- } \\
\text { tracting } \\
\text { legal and } \\
\text { ownership } \\
\text { problems }\end{array}$ & $\begin{array}{c}\text { The lack of } \\
\text { Costs }\end{array}$ & $\begin{array}{c}\text { Geometric } \\
\text { mean }\end{array}$ & $\begin{array}{c}\text { Standard } \\
\text { weight }\end{array}$ & $\begin{array}{c}\text { Original } \\
\text { weight }\end{array}$ \\
\hline $\begin{array}{c}\text { The possibility of con- } \\
\text { tracting }\end{array}$ & 1 & 1 & 0.2 & 0.58 & 0.14 & 0.014 \\
\hline $\begin{array}{c}\text { The lack of legal and } \\
\text { ownership problems }\end{array}$ & 1 & 1 & 0.2 & 0.58 & 0.14 & 0.014 \\
\hline Ownership Costs & 5 & 5 & 1 & 2.92 & 0.72 & 0.072 \\
\hline
\end{tabular}

Table 9. The binary comparison of urban criteria

\begin{tabular}{|c|c|c|c|c|c|c|}
\hline Row & $\begin{array}{c}\text { sensitive } \\
\text { points }\end{array}$ & Traffic & $\begin{array}{c}\text { Communication } \\
\text { paths }\end{array}$ & $\begin{array}{c}\text { Geometric } \\
\text { mean }\end{array}$ & $\begin{array}{c}\text { Standard } \\
\text { weight }\end{array}$ & $\begin{array}{c}\text { Original } \\
\text { weight }\end{array}$ \\
\hline sensitive points & 1 & 7 & 5 & 3.27 & 0.73 & 0.21 \\
\hline Traffic & 0.14 & 1 & 0.33 & 0.36 & 0.08 & 0.024 \\
\hline $\begin{array}{c}\text { Communication } \\
\text { paths }\end{array}$ & 0.20 & 3 & 1 & 0.84 & 0.19 & 0.056 \\
\hline \multicolumn{2}{|c|}{ total } & 4.50 & 1 & 0.29 \\
\hline
\end{tabular}

Table 10. Metric coordinates of proposed points

\begin{tabular}{|c|c|c|c|c|c|c|c|}
\hline No. & ID & X & Y & No. & ID & X & Y \\
\hline 1 & KW1 & $5,240,519.15$ & $4,081,944.01$ & 16 & SR16 & $5,247,710.45$ & $4,077,103.85$ \\
\hline 2 & RW2 & $5,241,583.33$ & $4,080,498.56$ & 17 & SB17 & $5,244,593.92$ & $4,077,418.97$ \\
\hline 3 & SW3 & $5,242,342.68$ & $4,080,591.17$ & 18 & NB18 & $5,245,705.02$ & $4,079,192.63$ \\
\hline 4 & SW4 & $5,243,660.31$ & $4,080,072.58$ & 19 & NK19 & $5,246,036.94$ & $4,081,447.28$ \\
\hline 5 & RW5 & $5,242,416.77$ & $4,079,749.79$ & 20 & NK20 & $5,245,431.75$ & $4,080,824.28$ \\
\hline 6 & RM6 & $5,243,258.14$ & $4,078,876.00$ & 21 & NV21 & $5,245,208.55$ & $4,080,274.92$ \\
\hline 7 & KE7 & $5,249,702.11$ & $4,078,502.83$ & 22 & MS22 & $5,244,799.85$ & $4,078,777.89$ \\
\hline
\end{tabular}


Dr. Farzad Amiri.

\begin{tabular}{|c|c|c|c|c|c|c|c|}
\hline 8 & NK8 & $5,249,425.27$ & $4,080,094.57$ & 23 & NV23 & $5,247,424.17$ & $4,079,452.12$ \\
\hline 9 & NK9 & $5,249,397.49$ & $4,080,953.67$ & 24 & NP24 & $5,247,062.90$ & $4,080,636.63$ \\
\hline 10 & MS10 & $5,248,190.45$ & $4,077,636.32$ & 25 & NS25 & $5,242,396.60$ & $4,081,677.71$ \\
\hline 11 & MP11 & $5,247,328.44$ & $4,077,693.47$ & 26 & SV26 & $5,244,769.41$ & $4,079,702.89$ \\
\hline 12 & MN12 & $5,247,398.82$ & $4,079,011.36$ & 27 & MJ27 & $5,243,865.72$ & $4,078,200.67$ \\
\hline 13 & NJ13 & $5,246,991.62$ & $4,079,807.89$ & 28 & EV28 & $5,248,126.82$ & $4,079,687.03$ \\
\hline 14 & MB14 & $5,245,807.96$ & $4,078,511.25$ & 29 & SE29 & $4,077,868.01$ & $5,251,185.02$ \\
\hline 15 & SR15 & $5,245,184.08$ & $4,077,129.39$ & 30 & NE30 & $4,077,563.50$ & $5,245,964.59$ \\
\hline
\end{tabular}

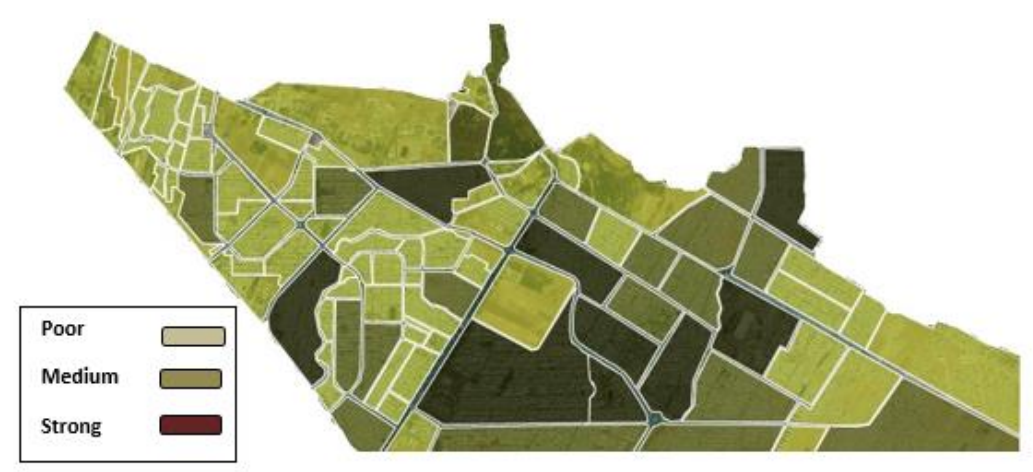

Figure 1. Integration of sub criteria and determination of priority criteria for construction and installation

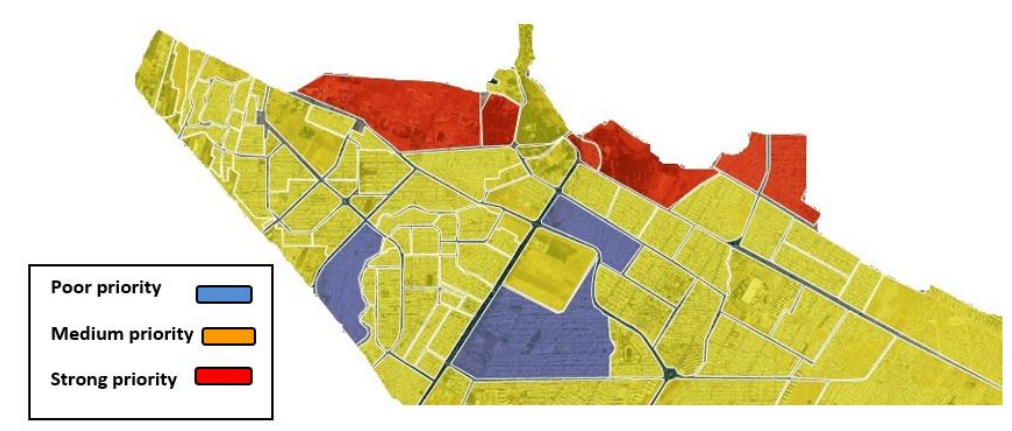

Figure 2. Integration of sub criteria and determination of priority criteria for construction and installation 


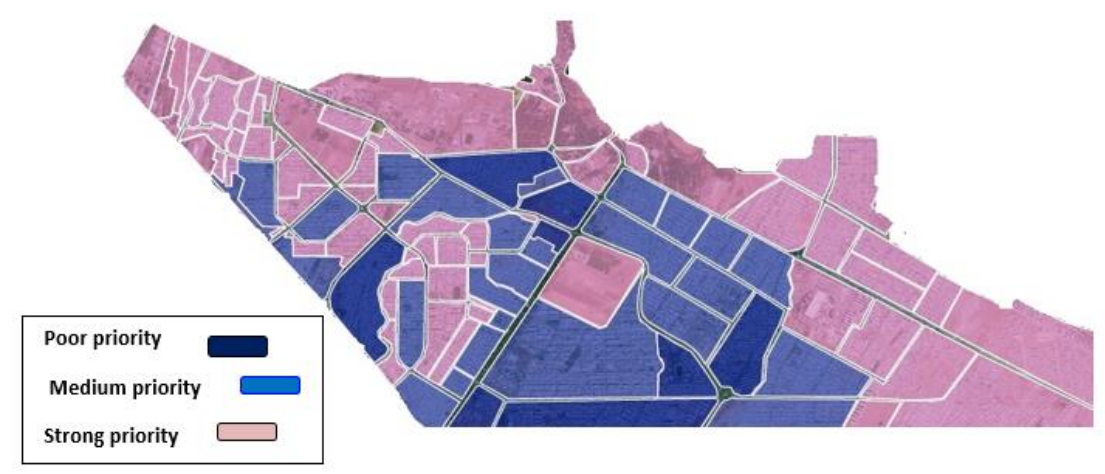

Figure 3. Identification of legal and ownership priorities

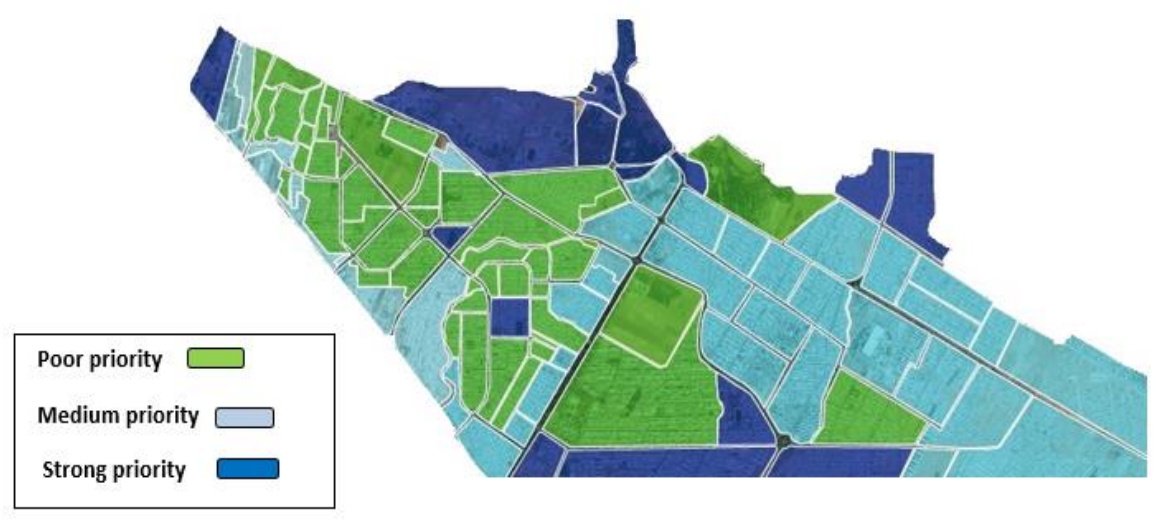

Figure 4. Determination of urban priorities

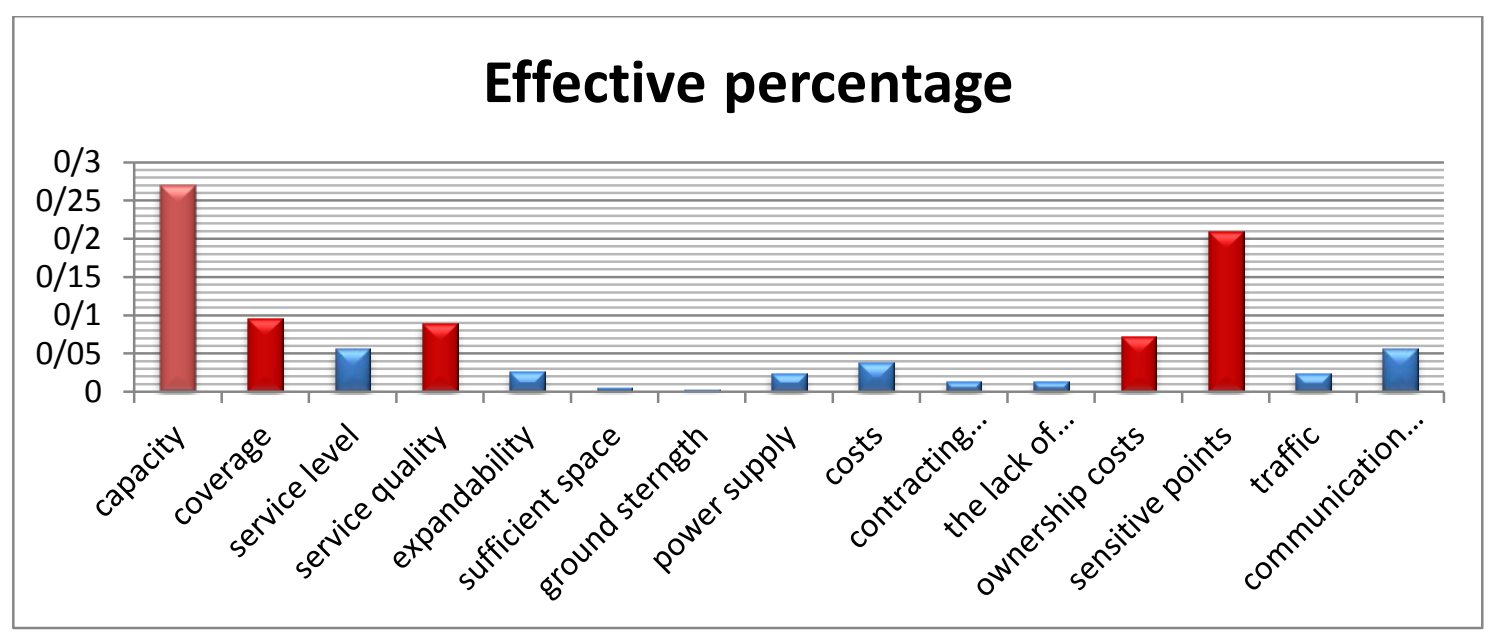

Figure 5. The effects of sub-criteria 


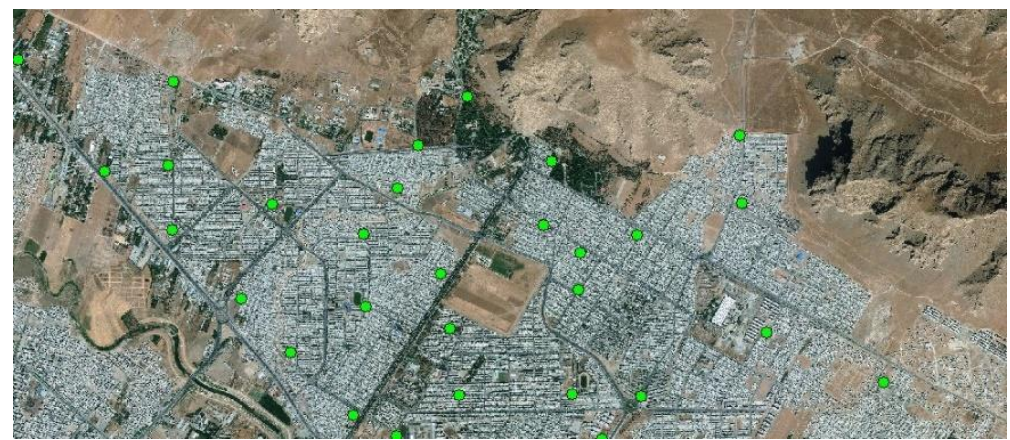

Figure 6. Determination of the proposed GIS coordinates to apply to the GA

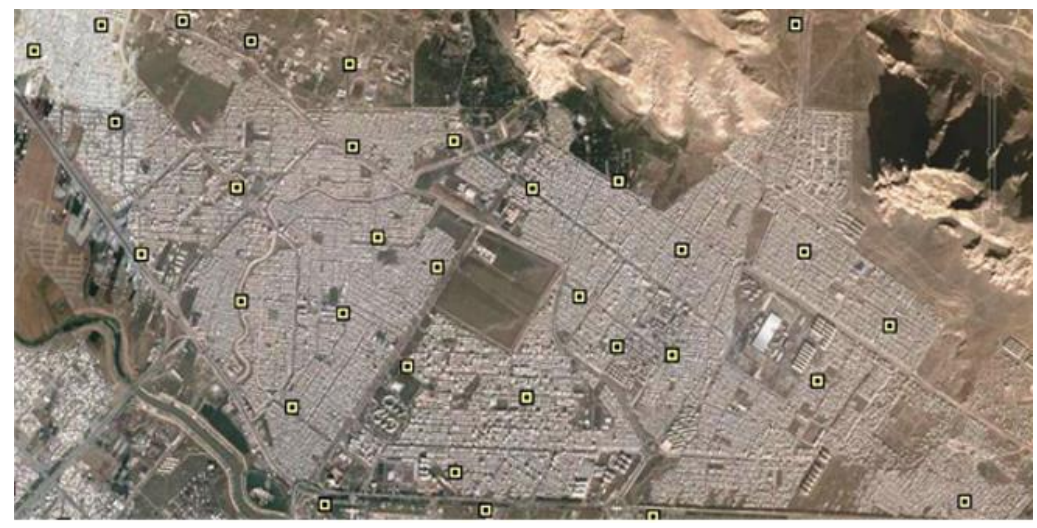

Figure 7. Location of BTS antennas in the north of Kermanshah at present

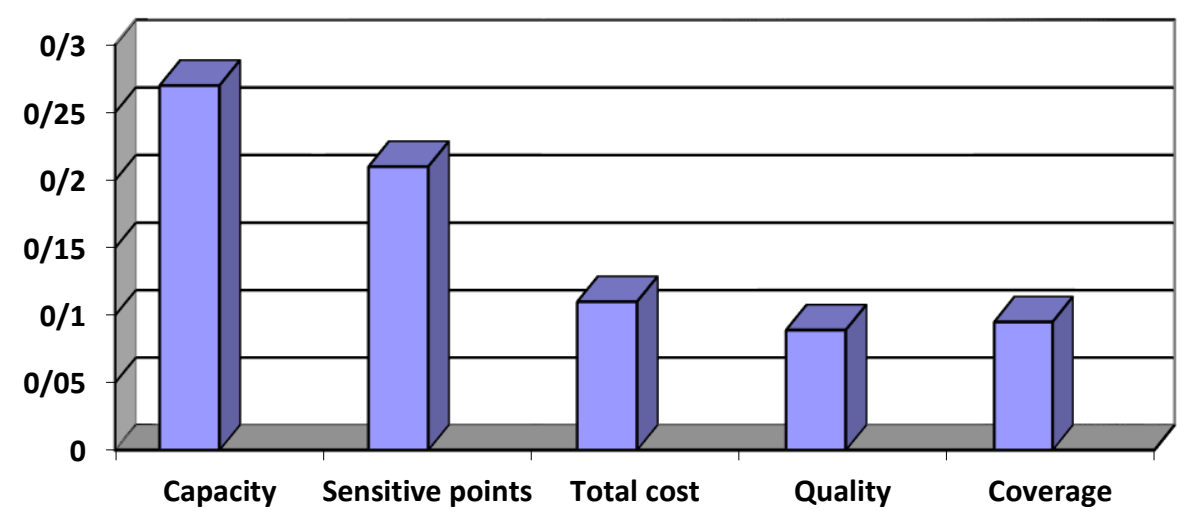

Figure 8. Important parameters 


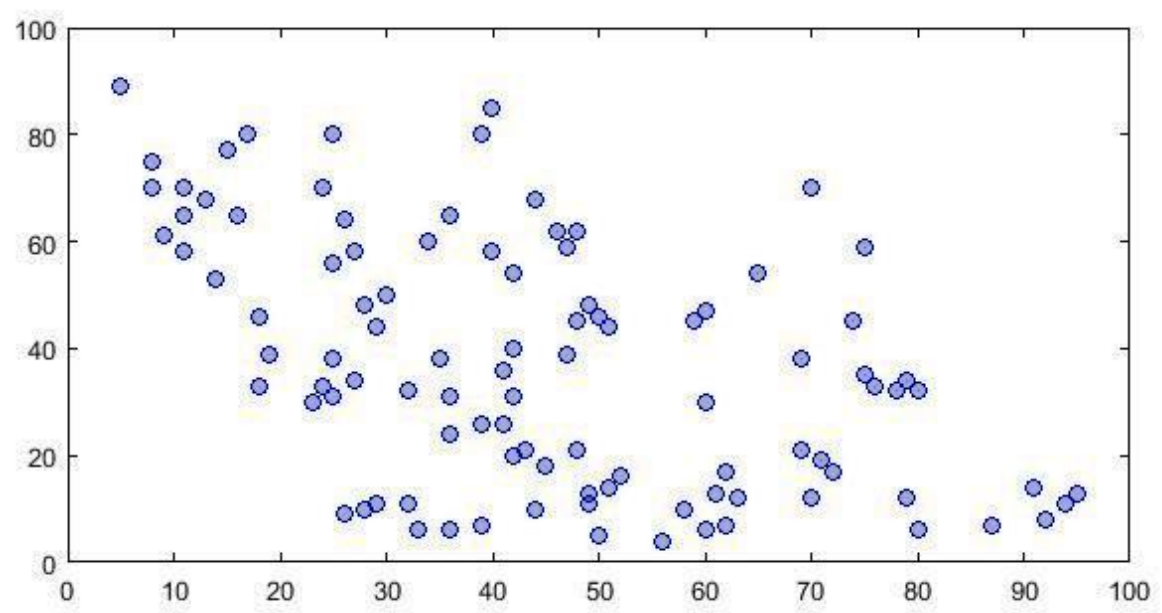

Figure 9. Accidental dispersion of users

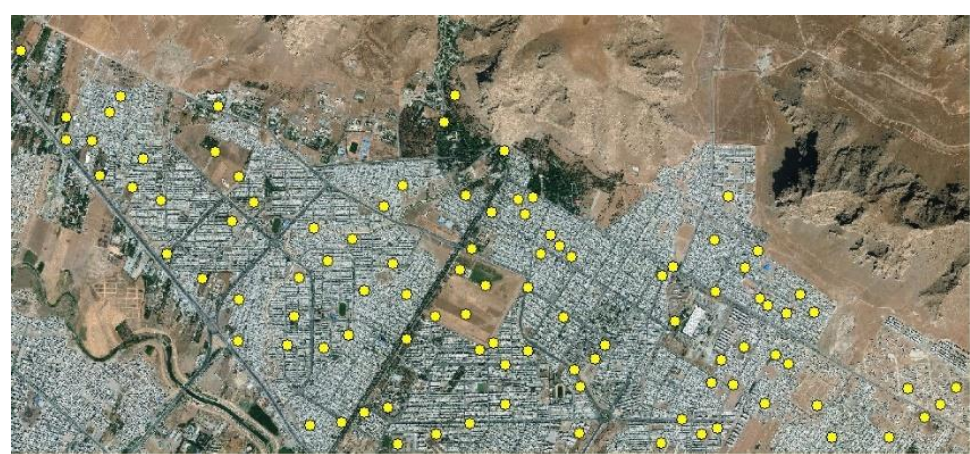

Figure 10. Random dispersion of users

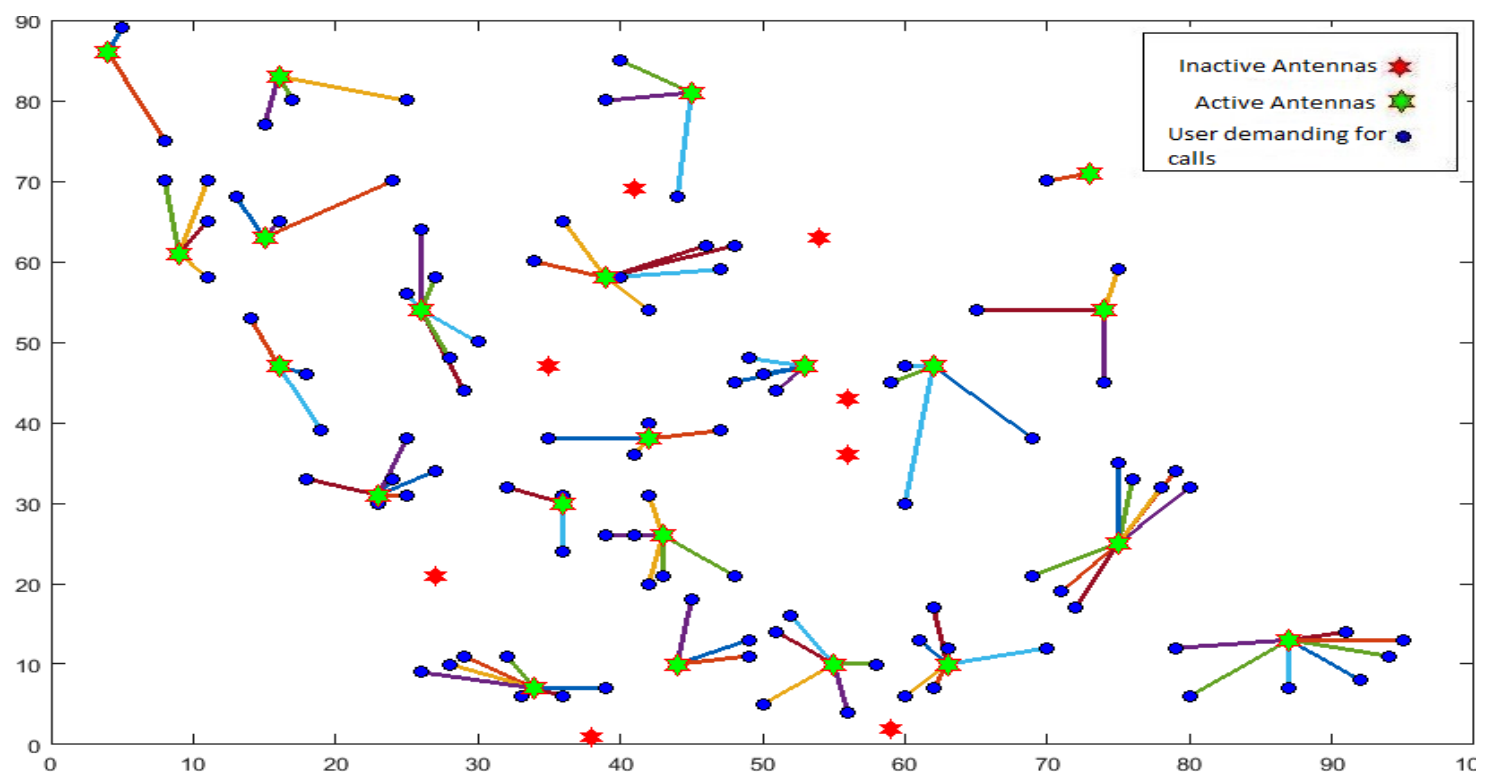

Figure 11. The number of active antenna using random selection 


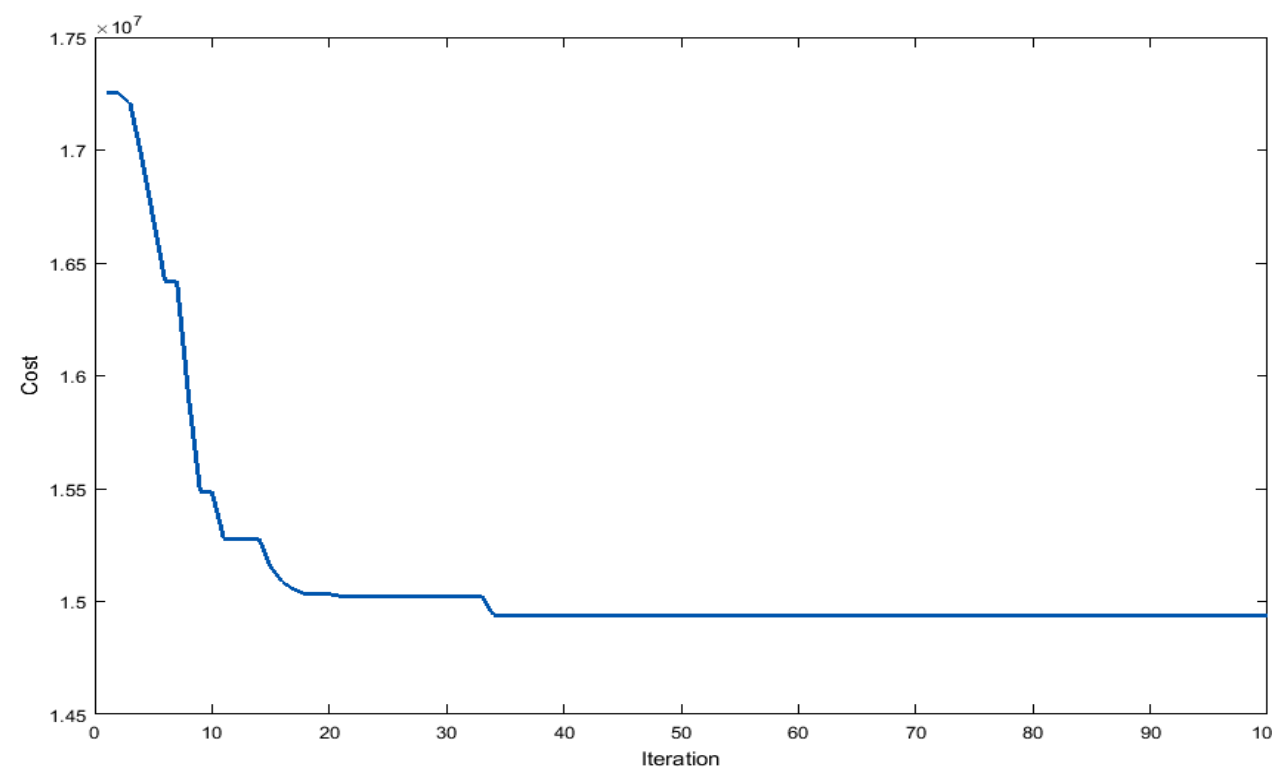

Figure 12. Reduced final cost obtained from repetition of the algorithm in random selection

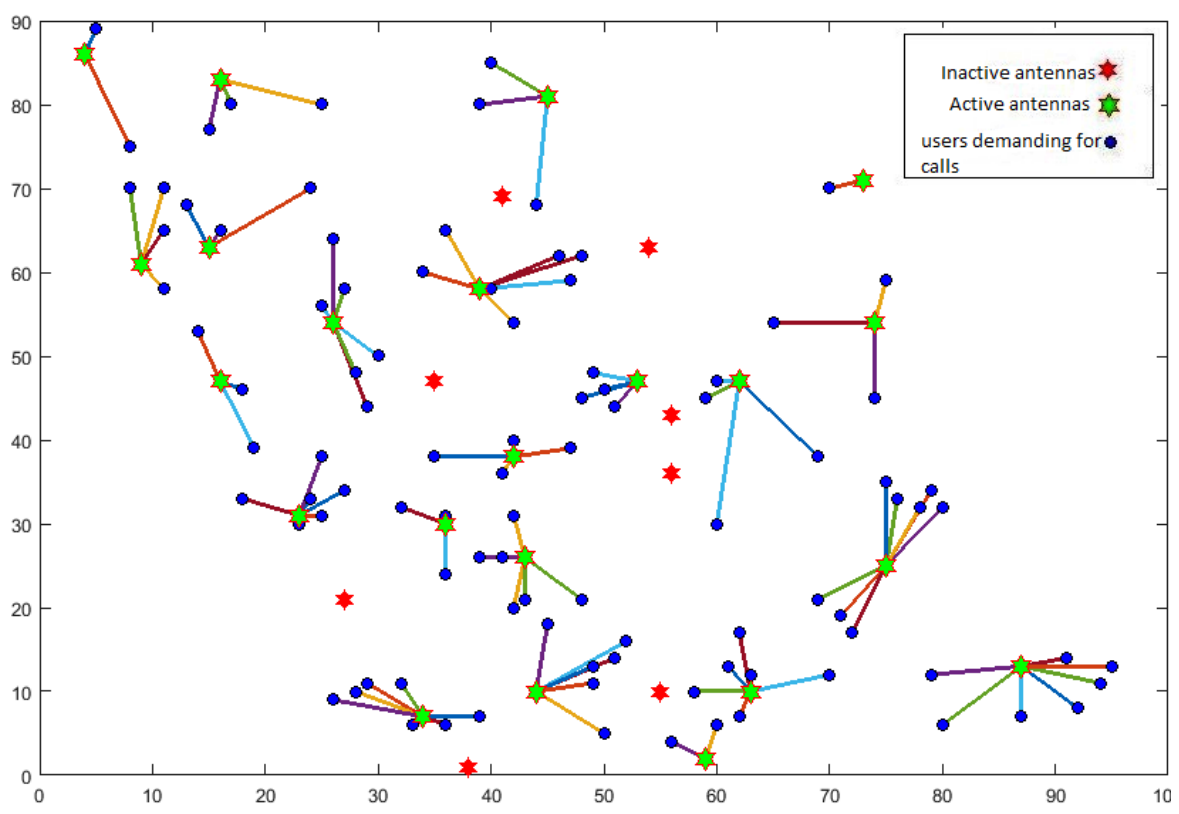

Figure 13. Active antenna number using tournament selection 


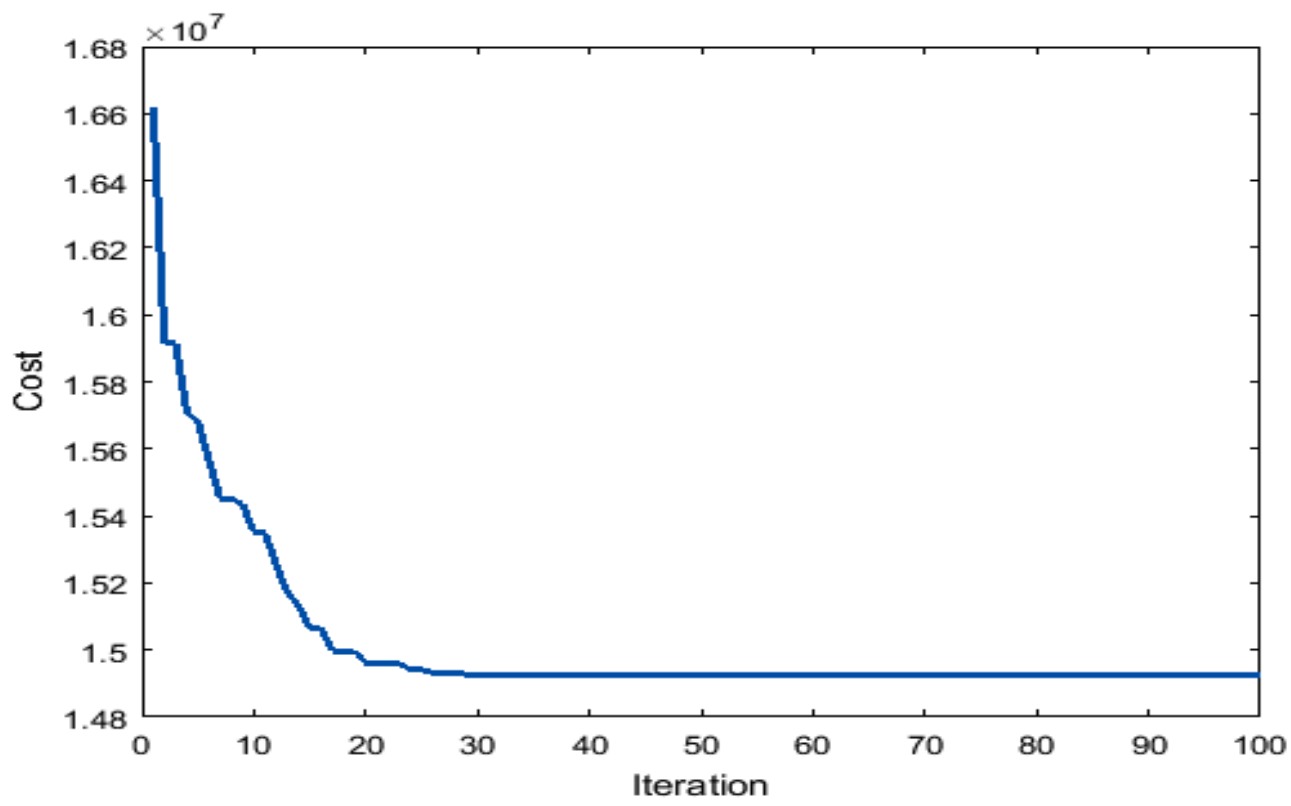

Figure 14. The amount of final cost reduced by the repetition of the algorithm through tournament selection

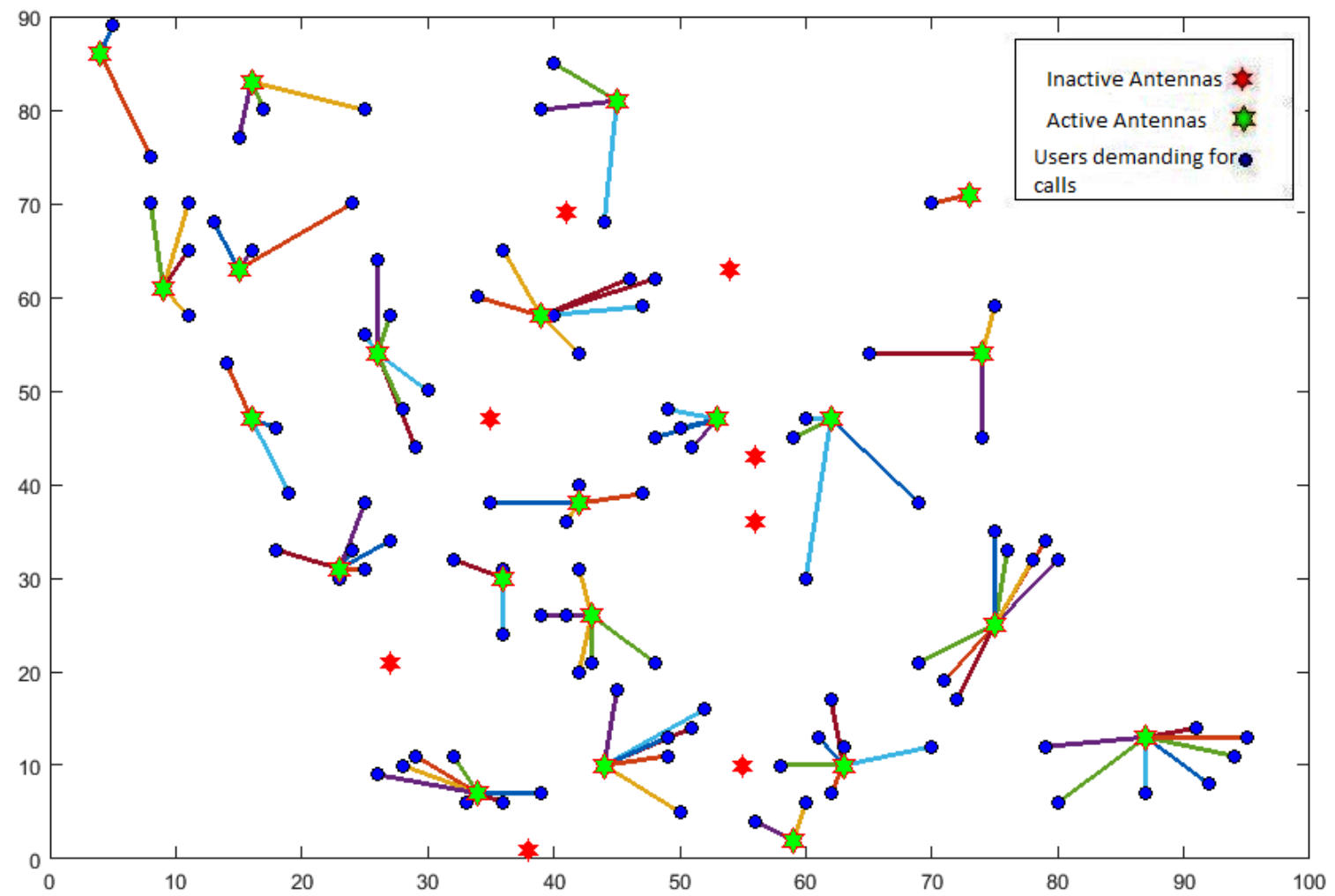

Figure 15. Active antenna number using roulette wheel selection method 


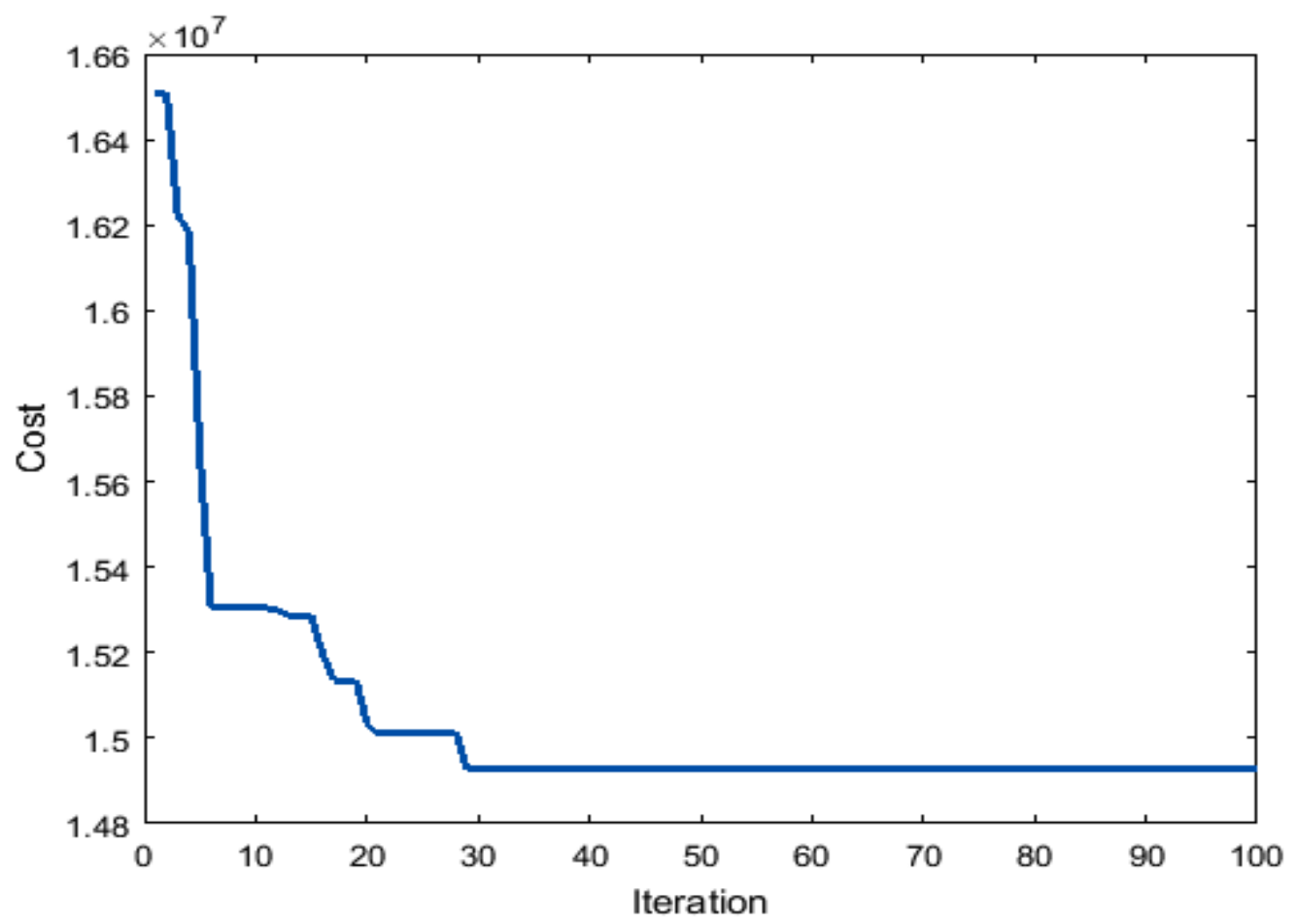

Figure 16. The amount of final cost reduced by the repetition of the algorithm through roulette wheel selection method

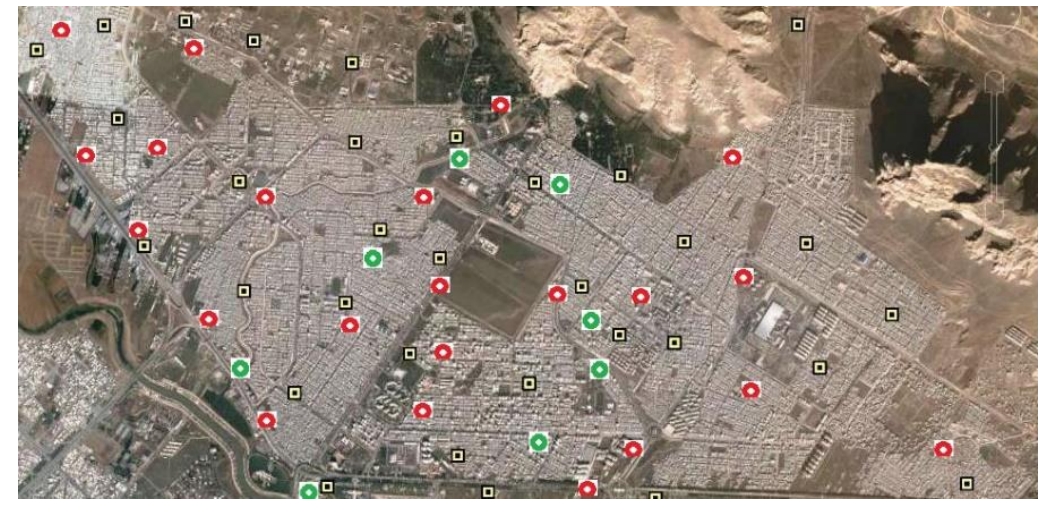

Figure 17. The best location of antennas according to the optimal output of the GA 